\title{
Results of the Kidney Transplant Programme at the University Clinical Centre of the Republic of Srpska from 2010 to 2018
}

\author{
Milorad Grujičićc, ${ }^{1,}$, Milan Žigić ${ }^{2,3}$, Milanko Maksić2,4, Slobodan Hajder³, Darko \\ Golić2,5, Branislav Gašić, Dragan Rakanović5, Novak Vasić2,4, Nataša Laganin ${ }^{3}$, \\ Zoran Roljić4, Ljubomir Stajčić ${ }^{6}$, Mirjana Mišković ${ }^{7}$, Dubravka Mićić-Zrnić1, \\ Goran Topić ${ }^{1}$, Vlado Đajić 8
}

\section{ABSTRACT}

Background: Kidney transplantation is the best treatment for patients with end-stage renal disease (ESRD). The aim of the study was to show the results of kidney transplantation performed in the University Clinical Centre of the Republic of Srpska in the period 2010-2018.

Methods: This was a retrospective, 8-year observational cross-sectional study. Studied endpoints were overall patient survival, as well as graft survival rate in kidney transplant recipients. Recipient's age, gender, induction immunosuppressive therapy, the underlying cause of ESRD, the dialysis modality and post-operative complications (surgical, medical, urinary tract infections, electrolyte imbalance, and graft rejection) and their influence on the patient and graft survival rates were monitored.

Results: The 30 living-donor kidney transplantations were performed, 29 livingrelated donor and one living-unrelated donor renal transplantation. A total of $70 \%$ of kidney recipients were male, and 30\% were female. The average age of patient was $34.43 \pm 8.67$ years. Induction immunosuppressive regimen was prescribed to $76.7 \%$ of transplanted patients. Graft rejection occurred in 5 patients (16.7\%). The 1-year, 3-year, 5-year, and 8-year patients survival rates were 100\%, 100\%, 96.97\% and $93.33 \%$, respectively. The 1-, 3-, 5-, and 8-year graft survival rates were $100 \%$, $96.97 \%, 93.33 \%$ and $86.67 \%$, respectively. The current mean value of glomerular filtration rate (GFR) in 25 patients with functional graft was $81.8 \pm 30.3 \mathrm{ml} / \mathrm{min}$. There was a statistically significant difference in the graft survival rate in the group with urinary tract infections (UTIs) (66.66\%) compared to a group without UTIs (100\%). Overall patient survival was significantly lower in the group with graft rejection (60\%) compared to the group without graft rejection (92\%). Kidney graft survival rate and overall patient survival have not been significantly different in terms of the studied factors (recipient's age, gender, induction immunosuppressive treatment, underlying cause of ESRD, dialysis modality, surgical or medical complications, and electrolyte imbalance).

Conclusion: The results of living-donor kidney transplantation performed in the University Clinical Center of the Republic of Srpska are good in comparison with the results obtained at other centres.

Key words: kidney transplantation; living donor; graft survival rate; patient survival.
(1) Department of Nephrology and Plasmapheresis, Clinic for Internal Medicine University Clinical Centre of the Republic of Srpska, Banja Luka, the Republic of Srpska, Bosnia and Herzegovina;

(2) Faculty of Medicine, University of Banja Luka, the Republic of Srpska, Bosnia and Herzegovina;

(3) Clinic for Vascular Surgery, Clinic for Urology, University Clinical Centre of the Republic of Srpska, Banja Luka, the Republic of Srpska, Bosnia and Herzegovina;

(4) Clinic for Vascular Surgery, UniversityClinical Center of the Republic of Srpska, Banja Luka, the Republic of Srpska, Bosnia and Herzegovina;

(5) Clinic for Anaesthesiology, University Clinical Centre of the Republic of Srpska, Banja Luka, the Republic of Srpska, Bosnia and Herzegovina;

(6) Department of Radiology, University Clinical Centre of the Republic of Srpska, Banja Luka, the Republic of Srpska, Bosnia and Herzegovina;

(7) Clinic for Psychiatry, University Clinical Centre of the Republic of Srpska, Banja Luka, the Republic of Srpska, Bosnia and Herzegovina;

(8) Clinic for Neurology, University Clinical Centre of the Republic of Srpska, Banja Luka, the Republic of Srpska, Bosnia and Herzegovina.

\section{Correspondence:}

MILORAD GRUJIČIĆ

E: grujicic-m@hotmail.com

M: +38765978030

\section{ARTICLE INFO}

Received: 21 May 2019 Revision received: 18 June 2019 Accepted: 24 June 2019

\section{INTRODUCTION}

Chronic kidney disease and its final stage, irreversible renal insufficiency (end-stage renal dis- ease, ESRD) are recognised as a worldwide public health concern (health as well as economic

Copyright $\odot 2019$ Grujucicic et al. This is an open access article distributed under the Creative Commons Attribution License (CC BY), which permits unrestricted use, distribution, and reproduction in any medium, provided the original work is properly cited. This article should be cited as follows: Grujičić M, Žigić M, Maksić M, Hajder S, Golić D, Gašić B, et al. Results of the kidney transplant programme at the University Clinical Centre of the Republic of Srpska from 2010 to 2018. Scr Med 2019;50(2):82-8. 
problem), after taking into account the annual costs of treatment per patient ${ }^{1}$. Kidney transplantation is the preferred treatment for most patients with ESRD, since transplanted patients have significantly better quality of life and increased life expectancy, as shown in several clinical trials ${ }^{2-5}$.

During the past 20 years, major changes have occurred in the Southeastern European countries regarding the area of kidney transplantation, as well as transplantation of other organs and tissues. Slovenia became a fully fledged member of Eurotransplant International Foundation in 2000, followed by Croatia in 2007 . Besides, transplantation medicine was rapidly progressing in these countries, so that by 2011 Croatia reached the highest level of the donor rate (number of cadaveric organ donors per million population [p.m.p.]), and nowadays, Croatia is one of the leading countries in the world regarding the transplantation rate ${ }^{6,7}$.

Another important step in the region that contributed to the development of the transplant programme in the Balkan region was the establishment of the South-Eastern Europe Health Network (SEEHN) in 2001. The SEEHN is a multi-governmental organisation of health systems represented by health authorities from Albania, Bosnia and Herzegovina, Bulgaria, Croatia, Israel, Moldova, Montenegro, North Macedonia, Romania, and Serbia. The Regional Health Development Centre on Organ Donation and Transplant Medicine (RHDC) was established in 2011 in Croatia to facilitate collaboration in deceased organ donation and transplantation. Kidney transplant programmes have grown dramatically in the period from 2011 to 2014 in five SEEHN member countries. Living donor kidney transplant programmes have been successfully launched in Montenegro and Moldova, and already established living kidney transplant programmes in North Macedonia, Bosnia and Herzegovina, Albania, and Romania have been markedly improved. At the same time, the number of kidney transplants from deceased donors in Romania, North Macedonia and Bulgaria increased due to an increase in the number of deceased donors.

Starting kidney transplantation and the establishment of transplantation program in the Republic of Srpska, one of the two entities of Bosnia and Herzegovina, represents a very im- portant qualitative step forward in the treatment of ESRD patients.

Kidney transplantation at the University Clinical Centre of the Republic of Srpska (UCC RS) was performed successfully with the help and mentoring of the experts from the Military Medical Academy (MMA), Belgrade, Serbia. The aim of the study was to show the results of kidney transplantation at the UCC RS in the period 2010-2018.

\section{METHODS}

The study was a retrospective, 8-year observational cross-sectional study covering the period from 2010 to 2018. It was performed at the Department of Nephrology of the Clinic for Internal Medicine of the UCC RS.

At the beginning of 2010, a cooperation agreement in the field of transplantation was signed between the two clinical centres: the UCC RS and the MMA, where it was agreed that surgical and internist transplant teams would be working together at the UCC BL, in order to gradually train our doctors for independent transplantation. The first transplantation was performed in June 2010. Complete preparation of the donor and kidney recipient was performed at the UCC $\mathrm{BL}$, and then the local surgical team (vascular surgeon, urologist), together with the MMA nephrologist, performed the renal transplantation at the UCC BL together with colleagues vascular surgeons, urologists, anesthesiologists, and nephrologists from the UCC BL. Post-operative monitoring and treatment of transplanted patients and donors was generally completed at the UCC BL.

Endpoints were patient and graft survival rates. Recipient's age, gender, induction immunosuppressive therapy, the underlying cause of ESRD, the dialysis modality and post-operative complications - surgical, medical, urinary tract infections (UTIs), electrolyte imbalance, graft rejection - and their influence on. ${ }^{9}$

The standard immunosuppressive regimen included corticosteroids, calcineurin inhibitors (generally tacrolimus), and mycophenolate. In the maintenance therapy, in one patient, tacrolimus was replaced with cyclosporine due to diabetes and visual impairment, and in two patients 
mycophenolate was replaced with azathioprine for planning pregnancy. Induction immunosuppressive therapy with basiliximab (Day o and Day 4) was given for the first two years in patients who had an increased immunological risk and, since 2013, in all patients.

A complete statistical analysis was performed using the statistical software PASW statistics 18. Attributed variables were presented as frequency of certain categories. Numerical variables were presented as mean with standard deviation. All the analyses were estimated at $\mathrm{p}<0.05$ level of statistical significance. Unadjusted graft and patient survival rates were calculated using Kaplan-Meier plots and p-values derived from the univariate Log-rank test.

Clinical and other protocols related to research have been adhered to.

\section{RESULTS}

A total of 30 living-donor kidney transplantations were performed, 29 living-related donors and one living-unrelated donor renal transplantation. Preemptive kidney transplantation was performed in three patients (10\%). In 27 patients renal transplantation was implemented after the onset of long-term dialysis. A total of $70 \%$ of kidney transplant recipients were male, and $30 \%$ of them were female. The average age of patients was $34.43 \pm 8.67$ years. The most common cause of ESRD was chronic glomerulonephritis -18 patients (60\%) and other causes were hypertension, chronic pyelonephritis, vesicoureteral reflux (VUR), unknown underlying disease. Sociodemographic and clinical data were shown in Table 1.

Complications after kidney transplantation are shown in Table 2. The most common complications after kidney transplantation were UTIs (early-onset, late-onset or recurrent) - in 12 patients (40\%); surgical complications were present in 10 patients (paralytic ileus - 4, lymphocoele and perirenal hematoma - 1 and surgical suture dehiscence and retained part of surgical drain in the abdominal cavity upon its removal - 1). Except for patients with paralytic ileus and 1 patient with lymphocele who responded to the conservative treatment, others were successfully surgically treated, some of them were managed during transplantation.

Medical complications were present in 10 patients: hypertensive crisis - 3 , acute gastritis and new-onset diabetes mellitus - 2 and negative drug interactions, fungal enterocolitis and

Table 1: Socio-demographic and clinical characteristics of kidney transplant recipients

\begin{tabular}{|c|c|}
\hline \multicolumn{2}{|l|}{ Gender: } \\
\hline male & $21(70.0 \%)$ \\
\hline female & $9(30.0 \%)$ \\
\hline Age (years); mean \pm standard deviation & $34.43 \pm 8.67$ \\
\hline \multicolumn{2}{|l|}{ Dialysis before transplant: } \\
\hline haemodialysis & $23(76.7 \%)$ \\
\hline peritoneal dialysis & $4(13.3 \%)$ \\
\hline preemptive transplant & $3(10.0 \%)$ \\
\hline \multicolumn{2}{|l|}{ Cause of the ESRD: } \\
\hline glomerulonephritis & $18(60.0 \%)$ \\
\hline hypertension & $6(20.0 \%)$ \\
\hline bilateral kidney angiomyolipoma & $1(3.3 \%)$ \\
\hline chronic pyelonephritis & $1(3.3 \%)$ \\
\hline unknown & $4(13.3 \%)$ \\
\hline \multicolumn{2}{|l|}{ Donor: } \\
\hline Living-related & $29(96.7 \%)$ \\
\hline Living-unrelated & $1(3.3 \%)$ \\
\hline \multicolumn{2}{|l|}{ Induction therapy: } \\
\hline yes & $23(76.7 \%)$ \\
\hline no & $7(23.3 \%)$ \\
\hline
\end{tabular}

Table 2: Post-operative complications in kidney transplant recipients

\begin{tabular}{lc}
\hline Surgical complications & $10(33.3 \%)$ \\
\hline Medical complications & $9(30.0 \%)$ \\
Urinary tract infections & $12(40.0 \%)$ \\
\hline Graft rejection & $5(16.7 \%)$ \\
\hline Cytomegalovirus infection & $1(3.3 \%)$ \\
\hline Electrolyte imbalance & $6(20.0 \%)$ \\
\hline
\end{tabular}

drug-induced liver injury were observed in 1 patient.

Electrolyte imbalance (most commonly hypomagnesaemia or hypocalcaemia due to excessive post-operative polyuria) was present in six patients and was a likely cause of paralytic ileus. Graft rejection has occurred in five patients; a biopsy of the transplanted kidney was performed in two patients. Induction immunosuppressive therapy was administered to $23(76.7 \%)$ patients. 
Kaplan-Maier curves of overall survival of patients and their grafts are given in Figures 1 and 2 , respectively.

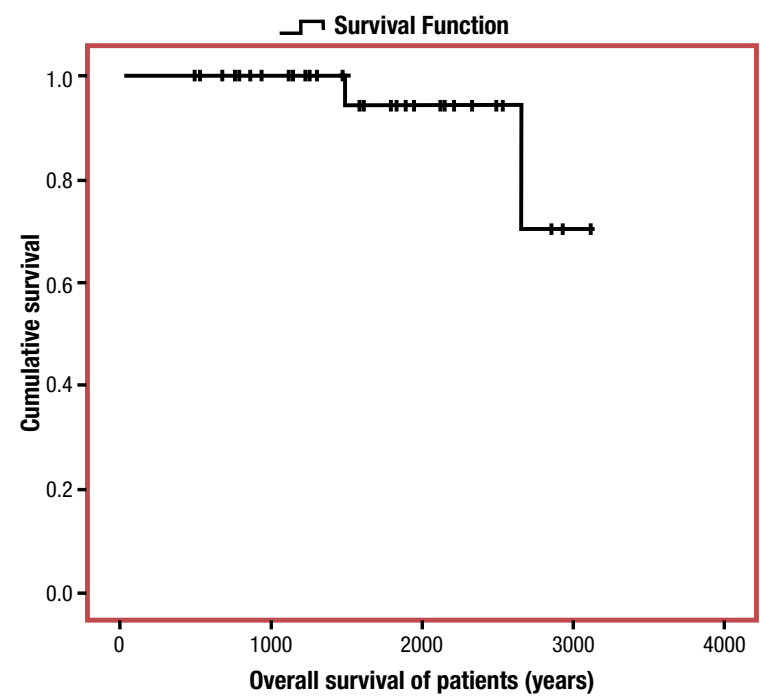

Figure 1. Overall survival in the patients with renal transplantation; means with 95\% confidence interval (Cl): 2919.53 (2668.06-3171.00) days.

One-, 3-, 5- and 8-year overall patient survival rates were $100 \%, 100 \%, 96.67 \%$ and $93.33 \%$, respectively.

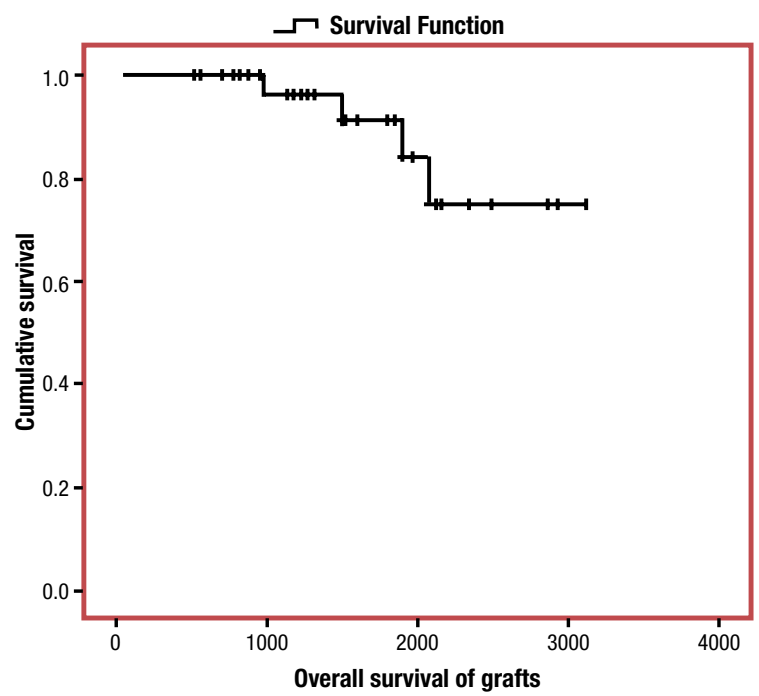

Figure 2. Cumulative graft survival rates in the transplanted patients; means with $95 \% \mathrm{Cl}$ : 2,729.99 (2,392.54-3,067.44) days.

One-, 3-, 5- and 8-year cumulative graft survival rates were $100 \%, 96.67 \%, 93.33 \%$ and $86.67 \%$, respectively.

There was a statistically significant difference in the graft survival rates between the group of patients with or without UTIs (Figure 3).

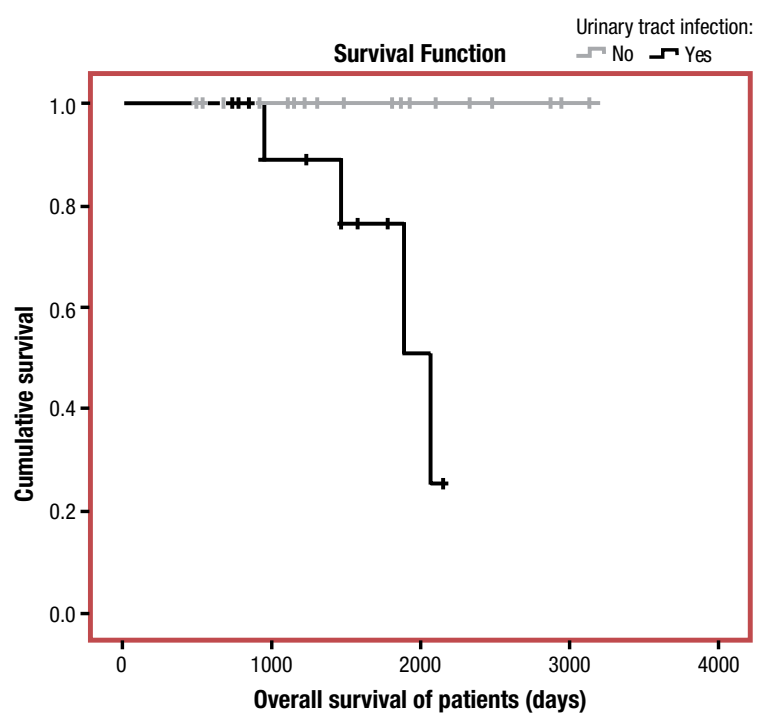

Figure 3. Cumulative graft survival rates in the transplanted patients according to the incidence of postoperative urinary tract infections (UTIS).

The graft survival rate in the group with UTIs was only $66.66 \%$, in comparison with $100 \%$ into the group without UTIs.

There was also a statistically significant difference in the patient survival rates between the group of patients with no graft rejection (25 patients) and the group of patients with graft rejection (Figure 4).

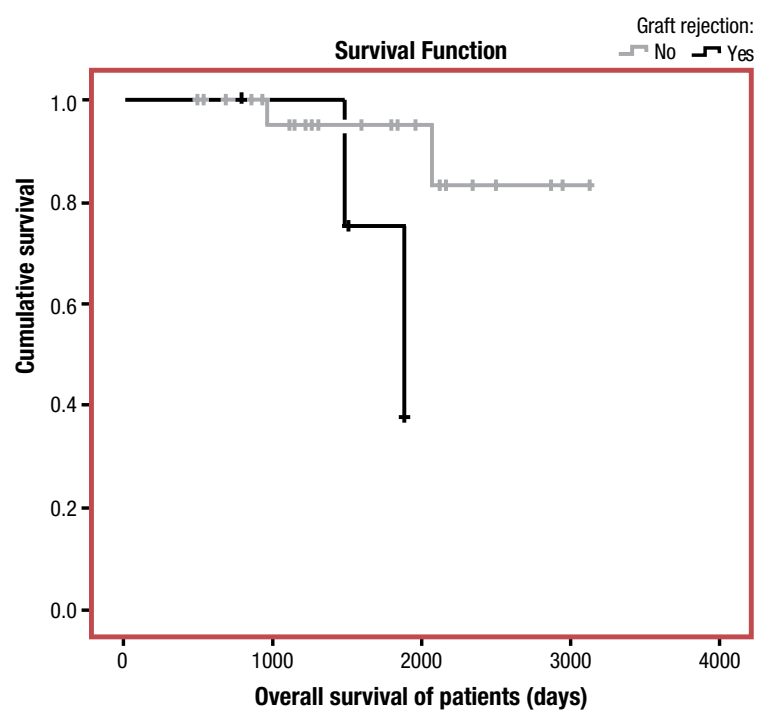

Figure 4. Cumulative graft survival rate in the transplanted patients according to the incidence of post-operative graft rejection; Log Rank test, $p=0.040$.

Overall patient survival was significantly lower in the group with graft rejection (60\%) compared to the group without graft rejection (92\%). The current mean value of glomerular filtration rate (GFR) in 25 patients with functional graft was $81.8 \pm 30.3 \mathrm{~mL} / \mathrm{min}$ (Table 3 ). 
Table 3: The most important outcomes of renal function in kidney transplant recipients

\begin{tabular}{lr}
\hline Recurrent ESDR & $4(13.3 \%)$ \\
\hline Death & $2(6.7 \%)$ \\
\hline Current glomerular filtration rate $\left(\mathrm{mL} / \mathrm{min} / 1.73 \mathrm{~m}^{2}\right) ;$ & $81.80 \pm 30.34$ \\
mean \pm standard deviation & \\
\hline ESRD = end-stage renal disease &
\end{tabular}

Two patients died: one due to a sepsis after massive pneumonia (with a functional graft) and the second one due to a stroke (developed 1.5 years after graft failure; Table 3). Three patients returned to dialysis after graft failure: one due to humoral rejection (proven by biopsy) that did not respond to the administered therapy, one due to vague thrombosis of the iliac artery and renal artery and one due to the unknown causes (with already present end-stage graft failure at the scheduled follow-up visit 1.5 year after kidney transplantation).

\section{DISCUSSION}

In the present study, the 1-, 3-, 5- and 8-year overall survival of the patient with a transplanted kidney, as well as the cumulative graft survival rates at specified time-points were monitored.

The impact of various factors on the graft survival, such as recipient's age, gender, induction immunosuppressive therapy, the underlying cause of ESRD, the dialysis modality and the post-operative complications (surgical, medical, UTIs, electrolyte imbalance, graft rejection) was also investigated.

Meta-analysis by Tonelli et al. ${ }^{10}$ included 110 worldwide published studies with 1,961,904 patients who were on chronic haemodialysis or were transplanted; $79 \%$ of these studies showed that there was a statistically significantly higher mortality risk for dialysis patients (regardless of the dialysis modality) compared to transplanted patients; in the other $21 \%$ of studies that difference was not statistically significant.

In the study by Gondos et al. ${ }^{11}$, the first comparative graft survival in cadaveric transplants in Europe and the United States was monitored. Overall, 1-year graft survival for cadaveric transplants in Europe was 90.6\% compared to US data as follows $91.5 \%$ for Latino-Americans, 91.1\% for American whites and $88.7 \%$ for Amer- ican blacks. Five- and 10-year graft survival in Europe was 77.0, and 55\%, respectively; for Latino-Americans in the USA these rates were $72.9 \%$ and 48.2\%, respectively; for American whites 71.3 and $45.7 \%$, respectively; and for American black people 62.5 and $33.7 \%$, respectively. The study showed that one-year patient survival was similar in Europe and in the United States, but overall patient survival was significantly higher in transplanted European patients compared to American ones.

In the study by Davila et al. ${ }^{12}$ (Colombian authors), 5-year survival of 164 transplanted patients was monitored; reported 5-year patient overall survival was $92.1 \%$ and 5-year graft survival was $88.4 \%$. The average age of transplant patients was 48 .

Effects of patient's gender, age, presence of opportunistic infections, surgical and immunological complications, donor type (cadaveric transplantation was performed in $84.8 \%$ of patients and living-donor transplantation was performed in $15.2 \%$ of patients), the presence of cytotoxic antibodies on 5-year overall patient survival as well on graft-survival rate were studied. They reported $18.9 \%$ of patients with graft rejection during the first post-operative year and risk ratio (RR) of graft loss in those who experienced rejection in the first year was significantly more $(p=0.002)$. Other monitored factors did not have a statistically significant impact on 5-year graft survival rate.

Slovenian authors ${ }^{7}$ reported $13.7 \%$ cases of acute graft rejection in the 1st year following transplantation for the period 2000-2016 for their 793 patients who have undergone cadaveric transplantation. In the study by Campbell et al. (Australian authors) ${ }^{13}$ the incidence of acute rejection in living-donor and cadaveric kidney transplantation was examined. Acute graft rejection was present in $44 \%$ of living-donor transplants and $28 \%$ of cadaveric transplants and was significantly more frequent $(\mathrm{p}<0.001)$ but there was no significant difference in graft survival rates for these groups.

Spanish authors Morales et al..$^{14}$ observed the effect of age on 5-year graft survival in 2,600 transplanted patients in 14 Spanish transplant centers. According to age, kidney recipients were classified in 3 groups: Group A: <40 years - 25.8\%; Group B: 40-60 years - 50.9\%; and Group C: $>60$ years $-23.19 \%$. Five-year survival 
rates were $97.4 \%, 90.8 \%$ and $77.7 \%$, respectively. The main cause of graft loss in patients aged $<40$ years was chronic allograft dysfunction, and in the other two groups death of patients with functional graft.

Nopakkun et al. ${ }^{15}$ observed the influence of donor age on 5 -year patient and graft survival in living-donor kidney transplantation in the United States. They reported the follows: hazard ratio (HR) of graft loss for donors aged 40-50 years was $1.777(p=0.032)$; HR of graft loss for donors aged between 50-60 years was 1.796 (p $=0.056$ ); and HR of graft loss for donors older than 60 was $2.611(\mathrm{p}=0.006)$. The patient's 1-year survival rate was $98.1 \%$ and the 5 -year survival rate was $93.8 \%$, while the 1- and 5-year graft survival rates were $94.3 \%$ and $87.5 \%$, respectively. The impact of UTIs in the 1st year after transplantation on the 1-year graft survival rate was followed by Bodro et al. ${ }^{16}$ and Golebievska et al. ${ }^{17}$. UTIs were reported in $36 \%$ of patients by Spanish authors, of which $15 \%$ had the most severe form of graft pyelonephritis.

Polish authors ${ }^{15}$ reported UTIs in 209 patients (53.1\%) in the first year after kidney transplantation. None of these two studies has been shown statistically significant effect on 1-year graft survival rate. In the current study, $40 \%$ of patients had UTIs in the 1st year following transplantation, which is comparable with the experiences of other authors. The percentage of graft rejection in the 1st year following transplantation in our patients was $16.6 \%$ (Colombian patients reported $18.9 \%$ ) and had a statistically significant impact on the graft loss in both studies.

If we compare the 5-year graft survival rates in transplanted European patients ${ }^{5}-77 \%$, in Colombian patients ${ }^{6}-92.1 \%$, in American whites - 85.4\%, obtained 5-year graft survival rates for our patients were $93.3 \%$. Good results of 1-year and 5-year survival in our patients can be explained by the selection of younger transplant patients (the average age of our recipient was 34.4 years, of the Colombian recipient was 48 years, of the recipients at the MMA was 44.5 years).

The limitation of the study is a small-sized sample, a short follow-up period (below 10 years) and thus a lower number of late complications, as well as retrospective design. In spite of these study limitations, its significance is very high be- cause good results were created by the cooperation of two clinical centres in Banja Luka and Belgrade.

\section{CONCLUSION}

Although the total number of kidney transplantations performed in the UCC RS is small, the obtained results are encouraging. Further monitoring of all factors that can influence the graft survival after living-donor renal transplantation as well as the development of cadaveric transplantation is required.

\section{ACKNOWLEDGEMENTS}

None.

\section{CONFLICT OF INTEREST}

None.

\section{REFERENCES}

1. Jha V, Garcia-Garcia G, Iseki K, Li Z, Naicker S, Plattner B, et al. Chronic kidney disease: global dimension and perspectives. Lancet 2013;382(9888):260-72.

2. Wolfe RA, Ashby VB, Milford EL, Ojo AO, Ettenger $\mathrm{RE}$, Agodoa LY, et al. Comparison of mortality in all patients on dialysis, patients on dialysis awaiting transplantation, and recipients of a first cadaveric transplant. N Engl J Med 1999;341(23):1725-30.

3. Laupacis A, Keown P, Pus N, Krueger H, Ferguson B, Wong C, et al. A study of the quality of life and cost-utility of renal transplantation. Kidney Int 1996;50(1):235-42.

4. Rusell JD, Beecroft ML, Ludurin D, Churcill DN. The quality of life and cost utility of renal transplantationa prospective study. Transplantation 1992;56:656-60.

5. Schnuelle P, Lorenz D, Trede M, Van Der Woude FJ. Impact of renal cadaveric transplantation on survival in end-stage renal failure: evidence for reduced mo tality risk compared with hemodialysis during longterm follow-up. J Am Soc Nephrol 1998;9(11):2135- 41.

6. Bašić-Jukić N. Bašić Jukić N. it is possible to maintain the highest number of transplantation in Croatia in the long term? BANTAO J 2013;11:49.

7. Kandus A, Buturović Ponikvar J, Mlinšek G, Oblak M, Arnol M. Kidney transplantation in Slovenia from 1970 to 2015. Ther Apher Dial 2016;20(3):229-33. doi: 10.1111/1744-9987.12428

8. Spasovski G, Busic M, Pipero P, Sarajlic L, Subotic Popovic A, Delmonico F, et al. Current status of tranplantation and organ donation in the Balkans-could it be improved through the South-Eastern European 
Health Network (SEEHN) initiative? Nephrol Dial Transplant 2012;27:1-5.

9. Brunet M, van Gelder T, Åsberg A, Haufroid V, He selink DA, Langman L, et al. Therapeutic drug monito ing of tacrolimus-personalized therapy: second consensus report. Ther Drug Monit 2019;41(3):261-307.

10. Tonelli M, Wiebe N, Knoll G, Bello A, Browne S, Jadhav D, et al. Systematic review: kidney transplantation compared with dialysis in clinically relevant outcomes. Am J Transplant 2011;1(10):2093-109.

11. Gondos A, Döhler B, Brenner H, Opelz G. Kidney graft survival in Europe and the United States: strikingly different long-term outcomes. Transplantation 2013;95(2):267-74.

12. Dávila FA, Luna RD, Rey DAP. Analysis of post-tranplant renal graft survival. Rev Colomb Nefrol 2015;2(2):95-100.

13. Campbell SB, Hothersall E, Preston J, Brown AM, Hawley CM, Wall D, et al. Frequency and severity of acute rejection in live- versus cadaveric-donor renaltransplants. Transplantation 2003;76(10):1452-7.
14. Morales JM, Marcén R, del Castillo D, Andres A, Go zalez-Molina M, Oppenheimer F, et al. Risk factors for graft loss and mortality after renal transplantation according to recipient age: a prospective multicentre study. Nephrol Dial Transplant 2012;27 Suppl 4: iv3946. doi: 10.1093/ndt/gfs544

15. Noppakun K, Cosio FG, Dean PG, Taler SJ, Wauters $\mathrm{R}$, Grande JP. Living donor age and kidney transplant outcomes. Am J Transplant 2011;11(6):1279-86.

16. Bodro M, Sanclemente G, Lipperheide I, Allali M, Ma co F, Bosch J, et al. Impact of urinary tract infections on short-term kidney graft outcome. Clin $\mathrm{Mi}$ crobiol Infect 2015;21(12):1104.e1-8. doi: 10.1016/j. cmi.2015.07.019

17. Gołębiewska JE, Dębska-Ślizień A, Rutkowski B. Urnary tract infections during the first year after renal transplantation: one center's experience and a review of the literature. Clin Transplant 2014;28(11):1263-70. 